\title{
Fabrication of Prosthetic Feeding Plate as a Treatment Plan for Infant with Complete Unilateral Cleft Lip and Palate (Case Report)
}

\author{
Liana Rahmayani \\ Faculty of Dentistry, Universitas Syiah Kuala \\ Banda Aceh, Indonesia \\ liana.rahmayani@unsyiah.ac.id
}

\begin{abstract}
One of the most common birth defects is cleft lip and palate. Infants with cleft lip and palate suffer from difficulty in feeding, due to lack of coordination between lips, tongue, and palate. This condition disrupts several functions including sucking, swallowing, aspiration and therefore inhibits infant's growth. Until now, there are still many patients that haven't received proper standard treatment. This is due to the failure to recognize and minister all aspects of health problems associated with this anomaly, inappropriate treatment time, and improper procedures. This case study reported a 2 -week-old infant that was born with a congenital defect of complete unilateral cleft lip and palate. Then, it was planned to fabricate a prosthetic feeding plate to help nurse the infant and guide the development of the cleft before it is ready for surgical reconstruction. The infant is a sensitive patient with high gagging reflexes. The impression was taken from patient and combination of Hotz plate and Kogo type prosthetic feeding plate was fabricated and inserted at the age of 6 weeks old.
\end{abstract}

Keywords-cleft lip and palate, congenital defect, prosthetic feeding plate, complete unilateral

\section{INTRODUCTION}

Congenital defects are birth defects. Cleft lip and palate defects are one of the most common birth defects that have an incidence of 1 per 800 to 1200 live births globally. Cleft lip and palate is a congenital defect of an abnormal cleft found on the face, especially on the lips and/or the palate. Cleft lip and palate occurs due to the failure of midfacial structure joining in the fourth to the tenth week of pregnancy $[1,2,3]$

Infants with cleft lip and palate suffer from feeding and nursing difficulties. Less efficient sucking ability when breastfeeding leads to the risk of choking as the milk may enter the airway or flowing out of nostrils. The presence of a cleft affects the ability to close the mouth and leads to inadequate sucking of fluids. The lack of coordination between the lips, tongue, and palate disrupts the function of sucking, swallowing, aspiration and therefore inhibits infant's growth $[1,3,4]$.

Other than feeding difficulties, patients also have several issues, such as impediment of speech, possibility of chronic ear infection, dental issues especially orthodontic, and also social and physiologic aspects [5,6]

Management of patients with congenital cleft lip and palate by surgical reconstruction has been agreed by the surgeon, but the surgery itself cannot be performed immediately as it must first fulfill the surgical requirements. Surgical cleft lip correction will be performed when the infant is able to accept surgical procedures. Generally, the surgeon holds on to the Rule of Ten to determine whether or not an infant is ready for surgery $[4,7,8]$. Achieving Rule of Ten requires adequate food intake, whereas in infants who suffer from cleft lip and palate will generally have difficulty in feeding and nursing so that their weight and overall growth will be reduced as well. Thus, a helping appliance, a feeding plate, should be made so they can eat and drink in a proper way. This appliance is a prosthodontics plate accurately made according to the anatomy of the jaw with a cleft palate so that it can cover the cleft [5]. This case report will discuss the treatment plans in an infant with congenital defects of cleft lip and palate by fabricating a prosthetic feeding plate, aimed to restore the condition of the separate palate and nose that will aid in terms of feeding.

\section{CASE REPORT}

A 7 days old male infant with weight $3 \mathrm{~kg}$, born with congenital birth defect of complete unilateral cleft lip and palate, was referred by an oral surgeon at the Zainal Abidin General Hospital (RSUDZA) for prosthetic management before the surgery to be done. The infant was planned to have a feeding plate that aimed to aid nursing him in the right way. His cleft lip and palate was quite large, the general condition of the infant was good, and there were no other abnormalities. His mother denied any trauma experience, the use of any drugs or traditional herbal medicine during her pregnancy. The infant is the $4^{\text {th }}$ child and there were history in the family that suffered the same condition.

\section{CASE MANAGEMENT}

Management of this infant includes an explanation to the parents about the defects/abnormalities experienced by their baby. Clinical examination will be done to observed the type of his cleft, the possibility of any infection in his oral cavity, ulceration which was usually present in the open nasal septum and if there was any swelling. Then, an impression will be taken on the maxillary defect. 
Before that, all the tools and materials needed to make an impression are prepared in advance, such as elastomer impression material, mixing slab, spatula, impression tray (custom tray precisely made to the size of the jaw), rubber bowl, gypsum spatula, and stone gypsum/type III gypsum for casting material (Figure 1). Before the impression was taken, the infant was consulted to the pediatric department in RSUDZA and received an approval to ensure the infant's health condition was safe for impression taking, while the infant's age at the moment was only about 2 weeks. Preparation of oxygen breathing apparatus and suction was coordinated together with an anesthesiologist. The infant was fasted for 2-3 hours prior the procedure to prevent gagging. Then the impression was taken in a conscious state without anesthesia or sedation. The impression was done by using elastomer impression material, then cast with stone gypsum to obtained the working model (Figure 2).

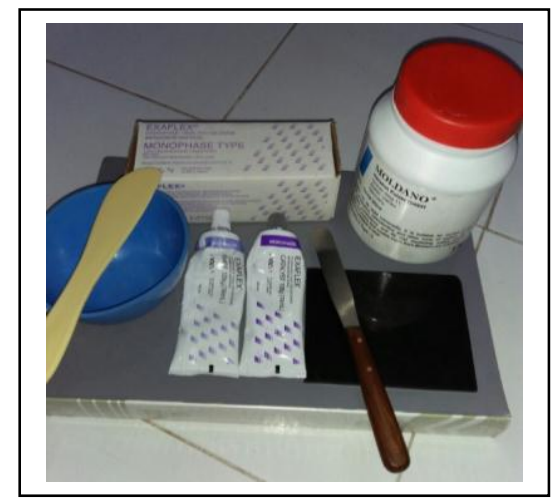

Figure 1. Tools and materials for impression.

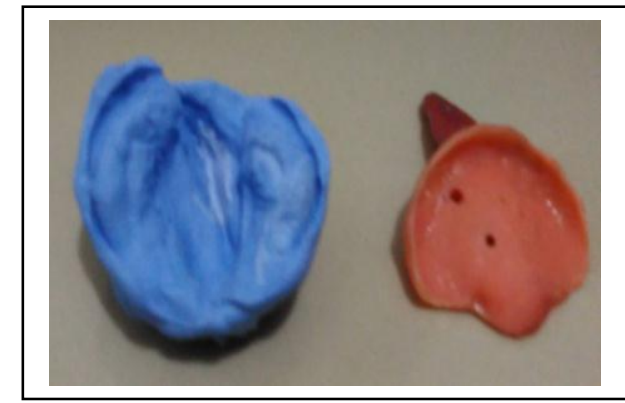

Figure 2. Working model and custom tray precisely made to the size of the jaw.

After we obtained the working model, the next step was laboratory process to fabricated the feeding plate with the combination of heat cured hard acrylic and soft acrylic. Wax pattern design was made with a combination of Hotz plate and Kogo type with 2-3 mm elevation in the posterior of the hard acrylic (mechanical surface) behind the hard palate so that the tongue can make contact with the plate when sucking. The completed feeding plate was polished before inserted to the infant (Figure 3).

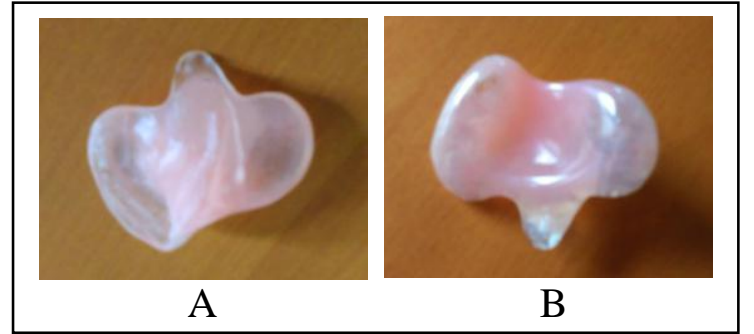

Figure 3. Combination of Hotz plate and Kogo type prosthetic feeding plate (A) The anatomical surface facing the palate (B) Polished mechanical surface.

The last procedure was the insertion of prosthetic feeding plate to the infants. In order to make sure that the infant would try to nursing using this appliance, the infant was asked to fasting 2-3 hours prior the insertion. At the time of insertion, the infant's age was over a month, so it was difficult to adapt the appliance. The infant has a high gagging reflex, so the posterior plate was reduced a lot to decrease the gagging reflex. After grinding, the infant has started adaptation with the feeding plate appliance (Figure 4), and started to learn to sucks. Parents were given instruction on how to insert and remove the appliance, and the appliance needs to be removed and cleaned after nursing.

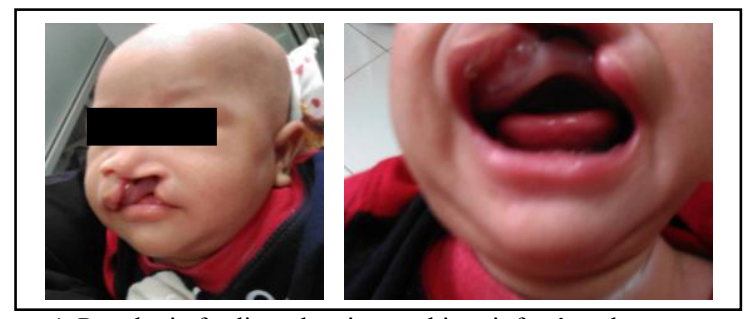

Figure 4. Prosthetic feeding plate inserted into infant's palate.

\section{DISCUSSION}

Issues associated with cleft lip and palate are disturbances in the process of food intake, impediment of speech, psychosocial developmental problems, malocclusion due to deformities of the maxillary region, and ear infections that may lead to deafness [2]. Orofacial abnormalities have potential to alter the ability to suck and swallow. The type of pressure and function of the oral structures involved in the process of food intake in infants. Infants with cleft lip have difficulty to close their lips tightly around the pacifier or nipple because of the defect, while infants with a cleft palate have difficulty in sucking milk. Infants with such condition require the use of feeding plate to facilitate sucking process as an effort to meet the nutrients needed [2,9].

The treatment plan for the infant in this case report begins with taking an impression on the upper jaw, which was done when the baby was 2 weeks old. Hotz and Gnoinski suggested that the proper time for taking an impression in infants with congenital cleft lip and cleft abnormalities should be done within 24-48 hours after birth and that the appliance should be inserted as soon as possible [10]. In this case, the impression was taken when the infant's age was more than the advisable age and it has shown an effect on the feeding plate appliance. In this 
case, the infant was more difficult to adapt at the moment of insertion. If the insertion was done as early as possible, then the infant's sucking reflex should have been better compared with infants who were older than a week, because the infant was not accustomed to drinking by sucking yet through a straw or pipette drops.

The prosthetics feeding plate fabricated for infants in this case report is a combination of Hotz plate and Kogo type. Hotz plate was made with an elongation at the posterior end of the plate, while the Kogo design was done by adding height in the posterior region. According to Kogo et al, they found that the design of these plates was determined by whether or not an intraoral pressure was created. The Kogo design was designed by adding 2-3 mm height to the mechanical surface of the hard palate so that the tongue can make contact with the plate during sucking and make the sucking movement better. The Hotz plate design often imperfectly seal the posterior region of the oral cavity, moreover in this case where the infant was having a quite high gagging reflex that the plate needs a lot of reduction or grinding in the posterior end. The posterior end becomes shorter so that the posterior region does not close completely. Thus the design of this feeding plate was made in combination so it was expected that the plate will be able to adapt to the infant's oral cavity [11].

Congenital defect of cleft lip and palate in infants can be handled in a prosthodontics way with the use of prosthetic feeding plate which aims to overcome the disturbance and difficulty in feeding intake for infants, help the process of speech and psychosocial problems.

Treatment plans for infants with cleft lip and palate can be done with several stages ranging from inspection, preparation for impression taking, laboratory process and insertion of prosthetic feeding plates in infants should be done as soon as possible.

\section{REFERENCES}

[1] N. Turagam, D.P. Mudrakola, S. Ugrappa, A. Jain, "Meeting the challenge of feeding a new born infant with cleft lip and palate-A case report," Dentistry, vol. 6, pp. 8, 2016.

[2] B.W. Neville, D.D. Damm, C.M Allen, J.E. Bouquot, Oral and maxillofacial pathology, $2^{\text {nd }}$ ed., Philadelphia: WB Saunders Com., 2002, pp. 2-4.

[3] (2011, November 22) Clef Lip and Cleft Palate. Available: <http://www.mayoclinic.org/diseases-conditions/cleft-palate/basics /symptoms/con-20024619>.

[4] L. Rahmayani, "Rehabilitation of congenital deformity cleft lip and palate with feeding plate," Cakradonya Dent. J., vol. 3, pp. 375-80, 2011.

[5] M. Rathee, A. Hooda, A.K. Tamarkar, S.P.S. Yadav, "Role of feeding plate in cleft palate: Case report and review of literature. The Internet Journal of Otorhinolaryngology, pp. 12, 2010.

[6] A. Chugh, D. Dahiya, H. Thukral, S. Verma, A. Ahlawat, A. Dahiya, "Different designs of feeding aids for cleft palatal defects," J. Health Edu. Res. Dev., vol. 4, pp. 3, 2016.

[7] (2011, November 22) Cleft Lip and Palate. Available: <http://en.wikipedia.org/wiki/Cleft_lip_and_palate>.

[8] B. Shi, J.E. Losee, "The impact of cleft lip and palate repair on maxillofacial growth," International Journal of Oral Science, vol. 7, pp. 14-17, 2015.

[9] L. Turner, C. Jacobsen, M. Humenczuk, V.K. Singhal, D. Moore, H. Bell, "The effects of lactation education and a prosthetic obturator appliance on feeding efficiency in infants with cleft lip and palate," Cleft Palate Craniofac J., vol. 38(5), pp. 519-24, 2001.

[10] D.T. Thomas, Clinical Maxillofacial Prosthetics. Illinois: Quintessence Publishing Co, 2000, pp. 63-73.

[11] M. Kogo, G. Okada, S. Ishii, M. Shikata, S. Iida, T. Matsuya (2017, September) Breast feeding for cleft lip and palate patients, using the Hotz-type plate. Cleft palate craniofac J. Available: <https://www.ncbi.nlm.nih.gov/pubmed/9257027>. 